\title{
The Long Run Relationship between Youth Population and Economic Growth: Evidences from Time Series Data of Bangladesh
}

\author{
S M Abdullah ${ }^{1} \&$ Sayema Haque Bidisha, ${ }^{1, *}$ \\ ${ }^{1}$ Dept. of Economics, University of Dhaka, Social Science Building (Second Floor), Dhaka - \\ 1000, Bangladesh \\ *Corresponding author: Dept. of Economics, University of Dhaka, Social Science Building \\ (Second Floor), Dhaka-1000, Bangladesh. Tel: 880-181-325-4771. E-mail: \\ sayemabidisha@gmail.com
}

Received: May 28, 2018 Accepted: June 15, 2018 Published: June 25, 2018

doi: 10.5296/rae.v10i2.13429 URL: https://doi.org/10.5296/rae.v10i2.13429

\begin{abstract}
With the help of forty three years time series data of Bangladesh, this paper attempts to understand the long term relationship between youth population and economic growth. Despite the significance of youth population to the economy, the long run relationship between the relative share of youth population to the economy and economic growth has not been analyzed in greater detail. In this context, this paper has applied Johansen cointegration analysis where the estimation result suggests that a consequential and proportional increase in youth population will lead to a rise in GDP growth in the long run. Given the significance of demographic composition on economic growth, the estimation results emphasized the importance of policies related to greater public investment in youth development programs including those of tertiary education and skill training initiatives.
\end{abstract}

Keywords: Youth Population, Economic Growth, Johansen Cointegration Analysis, Unit Root, VAR, VECM

JEL Classification: O15, I25, C32 


\section{Introduction}

There is no denying the fact that the composition of population of any country plays a crucial role in its growth and development prospects. In this context, due to its direct contribution to labour market, in particular, the proportional size as well as the trend of youth population is of further importance. From a global point of view, the world now hosts ever largest young people: aged between 10 to 24 and in many countries of the world, the proportion of youth to the population is also showing a rising trend (UNFPA, 2014). This increase in youth population is expected to raise the proportion of working age population of a country, which can act as a positive factor towards its growth. However it is often argued that the ability to confront the challenges of changed demographic composition depends on the appropriateness of institutions and policies and flexibility of the markets (Bloom et al. 2003).

In the context of Bangladesh, according to the Labour Force Survey 2013 (BBS, 2013), within the age group of 15 to 29 years, there was around 43.4 million people, so the youth population consisted of around 28 percent of total population of the country. From an initial high fertility-high mortality structure during 70's, Bangladesh with advancement in health care facilities and expansion of family planning programme, has eventually been able to significantly reduce birth rate as well as death rate. Life expectancy has also increased from 58.4 in 1990 to 71.6 in 2014 (World Bank). This rise in youth population has been reflected in the trend of youth labour force: from 19 million in 2002-03, with a decline in 2005 to 17.8 million, youth labour force (aged 15-29 years) has reached to 23.4 million in 2013 (LFS, 2013). This increased youth labour force if coupled with essential education and skill then it could turn into a vital factor for Bangladesh economy.

The increased policy focus on youth population is primarily due to the plausible positive impact of the proportional increase of working age population on economic growth-commonly referred as demographic dividend (Note 1). Increase in working age population (15 to 64 years) which consists of youth population (15 to 29 years) is argued to have direct effect on growth through increased labour market participation as well as indirect effect through higher savings and greater investment in human capital. This plausible growth enhancing effect of youth population however critically depends on the quality of youth population in terms of education, health and skill level. Based on such characteristics of population, the implications of rising trend of youth population on the growth prospects of a country can however be quite diverse.

Against this backdrop, this paper has utilized time series data of Bangladesh (1972-2014) and attempted to understand the long run effect of proportional increase in youth population on the growth of gross domestic product of the country. Despite of increased focus on the potential positive impact of youth population on national economy, to our knowledge there is scarcity in terms study examining such long run relationship for Bangladesh. From a methodological point of view, it has utilized standard time series econometric method to analyze the long run effect. 


\section{A Brief Review of Literature}

Although there has been increased acknowledgement of youth population's role in economic development, there is few country specific paper which has applied long run estimation techniques. Most of the studies have attempted to examine the potential effect of demographic transition on growth, instead of looking at the direct effect of youth population on growth per se. In addition, several studies have attempted to look at the effect of population growth on economic growth. In this context, with the time series data of Kenya Thuku et al. (2013) have estimated a VAR model to examine the relationship between population growth and economic growth and found a positive relationship between these two variables in the long run. The result therefore supported the hypothesis that population growth can act as a positive factor for the growth of the economy.

Roudi (2011) attempted to understand the development consequences of youth population in the context of Middle East and North Africa. Their analysis however utilized descriptive as well as graphical analysis instead of time series econometric methods. The findings emphasized the importance of a proper balance between social safety net programs and market mechanisms to utilize the youth population through better employment opportunities.

Iqbal (2015) with the help of data from Pakistan for the period 1974 to 2011 applied ARDL model and Bound Testing approach for cointegration analysis for understanding the consequences of demographic transition on economic growth. Their analysis revealed positive and significant impact of working age population on economic growth. Their analysis echoed similar result to that of Ali et al. (2013) who have also found positive impact of population growth on economic development.

In the context of Bangladesh, with the help of an unrestricted VAR and by using Granger Causality Test, Nakibullah (1998) have attempted to check whether population growth is endogenous or exogeneous in relation to economic development. His analysis revealed that, as for Bangladesh real GDP per capita tended to Granger cause population growth in Bangladesh but the reverse causality was not found to be valid. Based on this finding, the author concluded that population growth might be an endogenous factor in the development process of the country.

Ali et al. (2015) also have used annual time series data of Bangladesh for analyzing the relationship between population growth and economic development. They have estimated a simple growth model while applying OLS method and have found a negative impact of population growth on economic development. Their estimation however ignored time series properties of the variables under consideration and therefore should be interpreted with caution.

Ashford (2007) looked at the challenges as well as prospects of using the youth population in Sub-Saharan Africa for attaining demographic dividend. The study pointed out the importance of schooling both from a quantitative as well as qualitative point of view, emphasized about the prevention of early marriage, family planning programmes, amongst others to reap the benefits of increased youth population. 
While understanding the required policy focus to utilize the 1.8 billion adolscents and youths (10-24 years age), in report in UNFPA (2014), prime importance have been given to increased investment in youth development, along with ensuring gender equity and emphasizing on reproductive health and reproductive rights. However, the desired demographic dividend through youth population also requires supportive policy environment and economic structure that helps in ensuring macro stability and human capital accumulation, rule of law, enabling business environment etc.

\section{Data and Methodology}

The time frame of this analysis is from 1972 to 2014 and the data has been collected primarily from the World Development Indicators of the World Bank. This paper has attempted to examine whether there exist a long term equilibrium relationship among a number of variables contributing towards growth, particularly in this context, proportion of youths in total population of the country.

Based on a simple growth model with human capital as well as physical capital being the key factors of growth of a country, it involves standard time series econometric methods to detect long run equilibrium relationship among the chosen variables. Here, we include variables like, GDP growth (GDPG), GDP share of public spending on education (GDPSPSE); Secondary gross enrolment rate (SGER); GDP share of gross fixed capital formation (GDPSGFCF); GDP share of trade (GDPSTRADE) and proportion of youths in total population (RYP). Here, we should note that, in this analysis while following the classification of the labour force survey (LFS) of Bangladesh, we defined youth as those within the age range of 15 to 29 years.

\subsection{Identification of Integration Order of the Variables}

In time series econometric method, where the mean and auto-covariances of a series remain independent of time, it is characterized as stationary and before proceeding into any estimation it is essential to check the stationarity property of the variables used in estimation. In this regard, whenever a series is found to have unit root they can be characterized as nonstationary and the most common practice of transforming a nonstationary series into a stationary one is to take difference of that series. If a (nonstationary) series has to be differenced $d$ times for making it stationary then it can be termed as integrated of order $d$. In order to check order of integration, here we have used Augmented Dickey Fuller (ADF) (Dickey and Fuller, 1979) to test stationarity. In particular, the following test regression has been estimated for each of the variables:

$$
\Delta \mathrm{y}_{\mathrm{t}}=\mathrm{a}_{\mathrm{t}-1}+\sum_{\mathrm{i}=1}^{\mathrm{n}} \gamma_{\mathrm{i}} \Delta \mathrm{y}_{\mathrm{t}-\mathrm{i}}+\mathrm{x}_{\mathrm{t}}^{s} \delta+\mathrm{u}_{\mathrm{t}}
$$

Here, $y_{t}$ is the variable for which stationarity would be checked, $x_{t}$ are exogenous regressors consisting of either drift term or both drift and trend term and $\mathrm{u}_{\mathrm{t}}$ are assumed to be 


\section{Macrothink}

white noise. The coefficient of lagged variable, $\alpha=\rho-1$ and $\rho$ is the coefficient of autoregressive variable in a standard autoregressive regression model for $y_{t}$, The unit root hypothesis can be written as:

$$
\begin{gathered}
\mathrm{H}_{0}: \mathrm{d}=0 \text { implies } \rho=1, \mathrm{y}_{\mathrm{t}} \text { is Non Stationary } \\
\mathrm{H}_{1}: \mathrm{d}<0 \text { implies }|\rho|<1
\end{gathered}
$$

Thus the test is one sided. The Dickey - Fuller test statistic is the usual $\mathrm{t}-$ Statistic for $\mathrm{a}$ which is:

$$
\tau=\frac{\widehat{a}}{\operatorname{sE}(\widehat{a})}
$$

The Dickey - Fuller critical values has been used to take the decision.

\subsection{Selection of Lag Length}

If the variables under consideration are found to be integrated of same order (precisely, I(1)) then the long run equilibrium relationship can be established through a Vector Error Correction Model (VECM). In order to conduct such analysis, we need to check whether the variables are cointegrated or not following standard cointegration test which requires appropriate lag length selection. The selection of suitable lag length is important because introducing too many lags is argued to waste degrees of freedom, while too few lags might lead to the problem of misspecification and is likely to cause autocorrelation in the residuals. Here, the appropriate lag length was selected using a multivariate version of BIC and AIC. For lag length $p$ the relevant equation is as follows:

$$
\operatorname{BIC}(\mathrm{p})=\ln (\operatorname{det}(\widehat{\Sigma}))+\frac{\mathrm{k}(\mathrm{kp}+1) \ln (\mathrm{T})}{\mathrm{T}}
$$

Where, $\operatorname{det}(\widehat{\Sigma})$ is the determinant of $\widehat{\Sigma}=\frac{\sum_{\mathrm{t}=1}^{\mathrm{T}} \widehat{\varepsilon_{\mathrm{t}}} \widetilde{\varepsilon_{\mathrm{t}}}}{\mathrm{T}}$. The AIC is obtained by simply replacing $\ln (\mathrm{T})$ by 2 in the above formula.

\subsection{Johansen Cointegration Test}

The Johansen (1988) procedure is commonly used for the presence of multiple cointegrating vectors and for the speed of adjustment parameter. It relies on the relationship between the rank of a matrix and its characteristic roots and can be characterized as a multivariate generalization of Dickey - Fuller procedure (Enders, 2008). Consider the following generalization: 


$$
y_{t}=A_{0}+A_{1} y_{t-1}+\varepsilon_{t}
$$

It can be expressed in difference form as follows:

$$
\Delta \mathrm{y}_{\mathrm{t}}=\mathrm{A}_{0}+\pi_{\mathrm{y}_{\mathrm{t}-1}}+\varepsilon_{\mathrm{t}}
$$

Where, $y_{t}$ is a $\left(n^{*} 1\right)$ vector, $\left(y_{1 t}, y_{2 t}, \ldots, y_{n t}\right)^{r}, A_{0}$ is the (n*1) vector of constants $\left(\mathrm{a}_{10}, \mathrm{a}_{20}, \ldots \ldots, \mathrm{a}_{\mathrm{n0}}\right)^{\prime}, \varepsilon_{\mathrm{t}}$ is the $(\mathrm{n} * 1)$ vector of errors $\left(\varepsilon_{1 \mathrm{t}^{\prime}} \varepsilon_{2 \mathrm{t}^{\prime} \ldots \ldots,} \varepsilon_{\mathrm{nt}}\right)^{\prime}$ with mean zero and variance $\Sigma_{\varepsilon}$ and $\pi=\left(A_{1}-I\right)$ with $I$ as $\left(n^{*} n\right)$ identity matrix and $A_{1}$ as $(n * n)$ matrix of parameters. By allowing for higher order auto regressive process the above model can be written as:

$$
\Delta y_{t}=A_{0}+\pi_{y_{t-1}}+\sum_{i=1}^{p-1} \pi_{i} \Delta y_{t-i}+\varepsilon_{t}
$$

Where, $\pi=-\left(I-\sum_{i=1}^{p} A_{i}\right)$ and $\pi_{i}=-\sum_{j=i+1}^{p} A_{j}$. In the above process rank of $\pi$ matrix will be used to determine the number of independent cointegrating vectors. Therefore, if $\operatorname{rank}(\pi)=1$ then there is single cointegrating vector and $\pi_{y_{t-1}}$ is the error correction term and if $1<\operatorname{rank}(\pi)<n$ then there will be multiple cointegrating vector. In the above process we will be focusing on the estimate of autoregressive coefficient i.e. $\pi$ and its corresponding characteristics roots. For performing the test following two test statistics can be used:

$$
\begin{aligned}
& \lambda_{\text {trace }}(r)=-T \sum_{i=r+1}^{\mathrm{n}} \ln \left(1-\widehat{\lambda_{i}}\right) \\
& \lambda_{\max }(r, r+1)=-T \ln \left(1-\widehat{\lambda}_{r+1}\right)
\end{aligned}
$$

Here $\mathrm{T}$ indicates the used number of observations and $\widehat{\lambda_{i}}$ is the estimated values of characteristics roots or the eigen values obtained from $\pi$ matrix. $\lambda_{\text {trace }}$ is used to test null arguing that the number of distinct cointegrating vector is less than or equal to $r$ against a general alternative while $\lambda_{\max }$ test the same null against the alternative saying that there is $(\mathrm{r}+1)$ cointegrating vectors. 


\section{Summary Statistics}

Before proceeding into estimation, we first attempted to get insights about the key variables of our interest with the help of simple descriptive statistics for the full sample period (1972-2014) and as well as different sub sample periods (1972-80; 1981-90; 1991-00; 2001-10; 2011-14). Table 1 depicts that during early years the average GDP growth of the country was quite low (1.76 percent) with a high standard deviation. The average share of youth in total population (RYP) in the corresponding period was around 23 percent with low standard deviation (0.437). From a statistical point of view, the correlation coefficient of GDP growth and proportion of youth population was found to be negative but insignificant (0.477). During 80's GDP growth on an average increased along with RYP - their correlation was however still negative and insignificant. The decade of 90's has experienced an average GDP growth of above 4 percent and the average RYP during that period has increased further to more than 29 per cent as well resulting in a positive (but insignificant) correlation coefficient between the variables. The increase in average GDPG along with increase in RYP continued in the next decade too and during 2001 to 2011 the correlation coefficient between the variables turned out to be significant with a positive sign (0.708).

For the sample as a whole, during 1972 to 2014, the correlation coefficient was found to be 0.336 with a positive sign and being statistically significant. Our descriptive statistics therefore provides evidence of plausible positive impact of proportional increase in youth population in economic growth for Bangladesh and the impact of change in RYP on GDPG could be considered as a long run phenomenon for Bangladesh.

Table 1. Summary Statistics of Key Variables

\begin{tabular}{lccccc}
\hline & \multicolumn{2}{c}{ GDPG } & \multicolumn{2}{c}{ RYP } & \multirow{2}{*}{ Correlation (P - Value) } \\
\cline { 2 - 5 } \multicolumn{1}{c}{ Year } & Mean & Std. Deviation & Mean & Std. Deviation & \\
\hline $1972-80$ & 1.764 & 7.070 & 23.388 & 0.437 & $-0.477(0.193)$ \\
$1981-90$ & 4.021 & 1.549 & 26.984 & 1.453 & $-0.292(0.411)$ \\
$1991-2000$ & 4.680 & 0.624 & 29.024 & 0.139 & $0.443(0.198)$ \\
$2001-10$ & 5.578 & 0.994 & 29.472 & 0.129 & $0.708^{*}(0.021)$ \\
$2011-14$ & 6.265 & 0.264 & 28.977 & 0.169 & $0.840(0.160)$ \\
$1972-2014$ & 4.273 & 3.538 & 27.469 & 2.423 & $0.336^{*}(0.027)$ \\
\hline
\end{tabular}

Note: * indicates 5 percent level of significance

\section{Estimation Results}

\subsection{Stationarity Check}

Based on the discussion as outlined in Section 3, in Table 2 results of stationarity test following ADF procedure is shown where the test has been performed under three different specifications of test regression: one with no drift or trend, another one with only drift while the other with both a drift and a trend. As suggested by the results of Table 2, GDPG was 
found to be stationary at first difference in two test specifications; when none of the drift and trend considered and also when only drift was considered, hence it can be treated as an I(1) variable. As for RYP, the variable was also found to be difference stationary in two specifications (with both drift and trend term and without drift and trend term). Whereas, in case of only drift term, the result was found to be significant and stationary at level but non stationary and insignificant at first difference. However, considering both of the specifications, we can argue that the variable RYP could be treated as I(1). The ADF test statistics for first difference of all other variables i.e. GDPSPSE, SGER, GDPSGFCF and GDPSTRADE have been found to be statistically significant at both specifications, therefore they could also be characterized as difference stationary and hence I(1).

Table 2. ADF Test for Checking Stationarity

\begin{tabular}{|c|c|c|c|c|c|c|c|c|c|}
\hline \multicolumn{10}{|c|}{ ADF Test Results, Null Hypothesis: Series Contains a Unit Root } \\
\hline \multirow[t]{2}{*}{ Variables } & \multicolumn{3}{|c|}{ None } & \multicolumn{3}{|c|}{ Constant } & \multicolumn{3}{|c|}{ Constant and Trend } \\
\hline & $\begin{array}{c}\text { Test } \\
\text { Statistic }\end{array}$ & $\mathbf{P}$ & Stationarity & $\begin{array}{c}\text { Test } \\
\text { Statistic }\end{array}$ & $\mathbf{P}$ & Stationarity & $\begin{array}{c}\text { Test } \\
\text { Statistic }\end{array}$ & $\mathbf{P}$ & Stationarity \\
\hline GDPG & 0.458 & 0.80 & $\begin{array}{c}\text { Non } \\
\text { Stationary }\end{array}$ & -1.038 & 0.72 & $\begin{array}{c}\text { Non } \\
\text { Stationary }\end{array}$ & $-12.837^{*}$ & 0.00 & Stationary \\
\hline $\mathrm{D}(\mathrm{GDPG})$ & $-3.809^{*}$ & 0.00 & $\begin{array}{c}\text { Stationarity: } \\
\text { I(1) }\end{array}$ & $-3.786^{*}$ & 0.00 & $\begin{array}{c}\text { Stationarity: } \\
\text { I(1) }\end{array}$ & $-3.644^{* *}$ & 0.03 & Stationary \\
\hline GDPSPSE & -0.59 & 0.45 & $\begin{array}{c}\text { Non } \\
\text { Stationary }\end{array}$ & -0.993 & 0.74 & $\begin{array}{c}\text { Non } \\
\text { Stationary }\end{array}$ & -0.98 & 0.93 & $\begin{array}{c}\text { Non } \\
\text { Stationary }\end{array}$ \\
\hline $\begin{array}{l}\text { D(GDPSPS } \\
\text { E) }\end{array}$ & $-5.453^{*}$ & 0.00 & $\begin{array}{c}\text { Stationarity: } \\
\text { I(1) }\end{array}$ & $-5.418^{*}$ & 0.00 & $\begin{array}{c}\text { Stationarity: } \\
\text { I(1) }\end{array}$ & $-5.381^{*}$ & 0.00 & $\begin{array}{c}\text { Stationarity } \\
: \text { I(1) }\end{array}$ \\
\hline SGER & 1.789 & 0.98 & $\begin{array}{c}\text { Non } \\
\text { Stationary }\end{array}$ & 0.244 & 0.97 & $\begin{array}{c}\text { Non } \\
\text { Stationary }\end{array}$ & -2.972 & 0.15 & $\begin{array}{c}\text { Non } \\
\text { Stationary }\end{array}$ \\
\hline D(SGER) & $-2.991^{*}$ & 0.00 & $\begin{array}{c}\text { Stationarity: } \\
\text { I(1) }\end{array}$ & $-3.587^{*}$ & 0.01 & $\begin{array}{c}\text { Stationarity: } \\
\text { I(1) }\end{array}$ & $-3.787^{* *}$ & 0.02 & $\begin{array}{c}\text { Stationarity } \\
\quad: \mathrm{I}(1)\end{array}$ \\
\hline $\begin{array}{c}\text { GDPSGFC } \\
\mathrm{F}\end{array}$ & 4.336 & 1.00 & $\begin{array}{c}\text { Non } \\
\text { Stationary }\end{array}$ & -1.333 & 0.60 & $\begin{array}{c}\text { Non } \\
\text { Stationary }\end{array}$ & -2.378 & 0.38 & $\begin{array}{c}\text { Non } \\
\text { Stationary }\end{array}$ \\
\hline $\begin{array}{c}\text { D(GDPSGF } \\
\text { CF) }\end{array}$ & $-3.370^{*}$ & 0.00 & $\begin{array}{l}\text { Stationarity: } \\
\text { I(1) }\end{array}$ & $-4.697^{*}$ & 0.00 & $\begin{array}{l}\text { Stationarity: } \\
\text { I(1) }\end{array}$ & $-4.727^{*}$ & 0.00 & $\begin{array}{c}\text { Stationarity } \\
: \mathrm{I}(1)\end{array}$ \\
\hline $\begin{array}{c}\text { GDPSTRA } \\
\text { DE }\end{array}$ & 0.941 & 0.90 & $\begin{array}{c}\text { Non } \\
\text { Stationary }\end{array}$ & -0.504 & 0.88 & $\begin{array}{c}\text { Non } \\
\text { Stationary }\end{array}$ & -2.454 & 0.34 & $\begin{array}{c}\text { Non } \\
\text { Stationary }\end{array}$ \\
\hline $\begin{array}{c}\text { D(GDPSTR } \\
\text { ADE) }\end{array}$ & $-7.186^{*}$ & 0.00 & $\begin{array}{c}\text { Stationarity: } \\
\text { I(1) }\end{array}$ & $-7.544^{*}$ & 0.00 & $\begin{array}{c}\text { Stationarity: } \\
\text { I(1) }\end{array}$ & $-7.636^{*}$ & 0.00 & $\begin{array}{c}\text { Stationarity } \\
\quad: \mathrm{I}(1)\end{array}$ \\
\hline RYP & 0.767 & 0.87 & $\begin{array}{c}\text { Non } \\
\text { Stationary }\end{array}$ & $-3.704^{*}$ & 0.00 & Stationary & -1.419 & 0.83 & $\begin{array}{c}\text { Non } \\
\text { Stationary }\end{array}$ \\
\hline $\mathrm{D}(\mathrm{RYP})$ & $-1.720^{* * *}$ & 0.08 & $\begin{array}{c}\text { Stationarity: } \\
\text { I(1) }\end{array}$ & -1.995 & 0.28 & $\begin{array}{c}\text { Non } \\
\text { Stationary }\end{array}$ & $-5.590 *$ & 0.00 & $\begin{array}{c}\text { Stationarity } \\
\quad: \mathrm{I}(1)\end{array}$ \\
\hline
\end{tabular}

Note: ${ }^{*}$ indicates one percent level of significance, ${ }^{* *}$ indicates five percent level of significance and ${ }^{* * *}$ indicates ten percent level of significance. 


\subsection{Cointegration Analysis}

Based on the theories of time series econometric, since all of the variables were found to be of integrated of the same order they might form a cointegrating relationship among themselves. When variables form such linkage, then that indicates the existing of a long run equilibrium relationship. In order to check the presence of cointegrating relationship Johansen (1988) cointegration test is considered as the most popular estimation technique for testing long run relationship among time series variables. In order to conduct Johansen test, the first step is to check the lag structure of the variables that we should use in the model. In order to find the appropriate lag length we have first estimated an unrestricted VAR model and then minimized the multivariate version of SIC and AIC criteria for detecting the lag length (Table 3). As the results shows the AIC criteria supported for 4 lags whereas the BIC suggested 2 lags in the model. Here, we have chosen the lag length identified by BIC criteria as in large sample BIC is argued to indentify lag length more parsimoniously than its AIC counterpart.

Table 3. VAR Lag Structure Selection

\begin{tabular}{ccc}
\hline Lag & AIC & BIC \\
\hline Endogenous Variables: GDPG, RYP, GDPSGFCF, GDPSPSE, GDPSTRADE, SGER \\
\hline 0 & 24.009 & 24.265 \\
1 & 11.239 & 13.031 \\
2 & 9.072 & $12.399^{*}$ \\
3 & 8.670 & 13.533 \\
4 & $6.980^{*}$ & 13.379 \\
\hline
\end{tabular}

Note: * Indicates Lag Order selected by the respective criterion

In the next step of our analysis, we proceeded to identify the number of cointegrating vectors through the Johansen procedure. In this connection, we performed rank test using both Trace as well as Maximum Eigen Value method where the null hypothesis for the test is of Zero Cointegrating Rank or No Cointegrating Vector.

From Table 4 we could infer that the $\mathrm{p}$ values of the trace test of the hypothesis that 'Cointegrating Rank is Zero' was very low thus the hypothesis can be rejected. However, the null hypothesis of 'Cointegrating Rank Equals 4' could not be rejected at 5 per cent level as $p$ value is 0.111 . Therefore, we can conclude that there could be at most 4 cointegrating equations. The findings in favour of the existence of cointegrating relationship have remained same when we used the maximum eigenvalue approach, though the number of cointegratng equation identified by this approach has been found to be different from the earlier one. Here, as we have not been able to reject the hypothesis of 'Cointegrating Rank Equals Zero' at 5 per cent level when we hold it true that there are at most 3 cointegrating equations. 
Table 4. Johansen Cointegration Test

\begin{tabular}{ccccc}
\hline Hypothesized No. of CE(s) & Eigenvalue & Trace Statistic & 0.05 Critical Value & Prob.** \\
\hline & Unrestricted Cointegration Rank Test (Trace) & \\
\hline None* $^{*}$ & 0.6722 & 147.419 & 95.753 & 0.000 \\
At most 1* & 0.6114 & 102.800 & 69.818 & 0.000 \\
At most 2* & 0.5445 & 64.986 & 47.856 & 0.000 \\
At most 3* & 0.4001 & 33.525 & 29.797 & 0.017 \\
At most 4 & 0.2640 & 13.083 & 15.494 & 0.111 \\
\hline
\end{tabular}

Trace test indicates 4 cointegrating eqn(s) at the 0.05 level, $*$ denotes rejection of the hypothesis at the 0.05 level, **MacKinnon-Haug-Michelis (1999) p-values

\begin{tabular}{ccccc}
\hline Hypothesized No. of CE(s) & Eigenvalue & Max - Eigen Statistic & 0.05 Critical Value & Prob.** \\
\hline & Unrestricted Cointegration Rank Test (Maximum Eigenvalue) & \\
\hline None $^{*}$ & 0.6722 & 44.618 & 40.077 & 0.014 \\
At most $1^{*}$ & 0.6114 & 37.814 & 33.876 & 0.016 \\
At most 2* & 0.5445 & 31.460 & 27.584 & 0.015 \\
At most 3 & 0.4001 & 20.441 & 21.131 & 0.062 \\
At most 4 & 0.2640 & 12.261 & 14.264 & 0.101 \\
\hline
\end{tabular}

Max-eigenvalue test indicates 3 cointegrating eqn(s) at the 0.05 level, $*$ denotes rejection of the hypothesis at the 0.05 level, **MacKinnon-Haug-Michelis (1999) p-values

Table 5. Long Run Relationship

\begin{tabular}{ccccccc}
\hline \multicolumn{7}{c}{ Cointegrating Equation: Vector of Long Run Coefficients } \\
\hline GDPG & RYP & GDPSGFCF & GDPSPSE & GDPSTRADE & SGER & Constant \\
\hline \multirow{2}{*}{1.000} & $-0.431^{* *}$ & $0.784^{*}$ & $-1.648^{* *}$ & $-0.338^{*}$ & -0.087 & 6.387 \\
& $(0.193)$ & $(0.201)$ & $(0.614)$ & $(0.068)$ & $(0.045)$ & - \\
\hline
\end{tabular}

Note: ${ }^{*}$ indicates one percent level of significance, ${ }^{* *}$ indicates five percent level of significance. Standard Errors are in Parenthesis

With the cointegrating relationship among the variables, in the next step, we have attempted to develop a VECM model with a view to identifying the long run equilibrium relationship among the variables. In particular, our objective is to estimate the long run impact of the share of youth population to total population (RYP) on GDP growth (GDPG) and Table 5 in this regard contains the estimation results for long run coefficients. It is evident from our results that the long run coefficient attached with RYP is significant at 5 per cent level implying that there exists a long run equilibrium relationship between RYP and GDPG. RYP has been found as a significant variable as it might have positive impact on income growth in the long run. In particular, the findings reveal that an increase in RYP will lead to a rise GDPG in the long run. The long run impact of GDPSTRADE, GDPSPSE is found to be significant with proper sign. Most importantly the impact of GDPSPSE was found to be more than others implying the importance of investment in human capital from govt. perspective. 
Nevertheless, the long run impact of SGER was observed to be insignificant although the sign was proper and that of GDPSGFCF was significant with an opposite sign.

\subsection{Post Estimation Diagnostic Results}

In order to test autocorrelation in VECM residuals, we have applied Portmanteau test (Table 6). As per the method of time series econometrics a correctly specified VECM should contain sufficient lag variables so that residuals become independent of each other removing autocorrelation. According to Table 6, the test is invalid for the first two lags (as the lag length of estimated VECM is two). It can be inferred from the test results that due to high $\mathrm{p}$ values we cannot reject the null of no autocorrelation even up to $10^{\text {th }}$ lag implying that the VECM residuals are independent of each other and the estimated model is free of autocorrelation.

Table 6. Testing for Residual Autocorrelation in VECM

\begin{tabular}{ccc}
\hline Lag Order $(\mathbf{h})$ & Q - Stat. & Prob. \\
\hline & Null Hypothesis: No Residual Autocorrelation up to lag h & \\
\hline 1 & 9.294 & - \\
3 & 39.364 & - \\
4 & 71.930 & 0.288 \\
5 & 99.425 & 0.553 \\
6 & 131.491 & 0.639 \\
7 & 166.210 & 0.651 \\
8 & 190.735 & 0.825 \\
9 & 215.769 & 0.918 \\
10 & 245.773 & 0.941 \\
\end{tabular}

Another post estimation diagnostic which could remain as important is the 'spread' of VECM residuals. It is argued that the residuals should be distributed with constant variance in a VECM and in order to check it we applied LM test for homoscedasticity of VECM residuals

(Table 7). It can be observed that the value of test statistic $\left(\chi^{2}\right)$ is 520.349 with a $\mathrm{p}$ - value of 0.778. Therefore, there is not enough evidence against the homoscedasticity of estimated VECM residuals.

Finally, Figure 1 contains the plot of inverse AR roots which can be considered as a visual diagnostic of VECM stability. A stable process requires all the inverted roots to be strictly less than unity and to lie inside the unit circle except the number of unit modulus (i.e. conintegrating equation) VECM imposes. According to Figure 1, one of the inverted roots lies on the edge of the unit circle indicating VECM imposed one cointegrating equation. All 
the other inverted AR roots lies strictly inside the unit circle indicating that the model has been appropriately identified and establishing the stability of VECM.

Table 7. LM test of VECM Residuals

\begin{tabular}{cc}
\hline \multicolumn{2}{c}{ Null Hypothesis: No Heteroscedasticity in VECM Residuals } \\
\hline Test Statistic $\left(\chi^{2}\right)$ & Prob. \\
\hline 520.349 & 0.778 \\
\hline
\end{tabular}

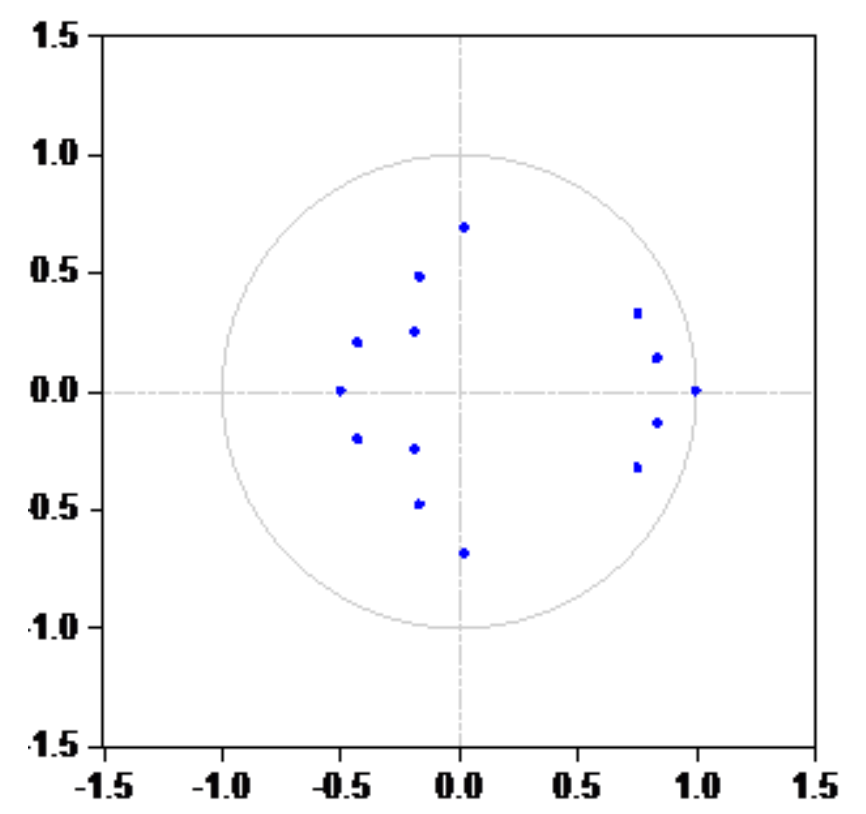

Figure 1. Plot of Inverse AR Roots in VECM

\section{Conclusion and Recommendations}

Based on our analysis, we can infer that, in case of Bangladesh, an increase in the proportional share of youth population to total population in the long run tends to have a positive and significant impact on economic growth. The analysis has included relevant variables in estimating growth model and has applied standard Johansen Cointegration analysis after performing stationarity check of the variables in estimation. The evidence of positive and significant long run impact of youth population on economic growth of the country provides indication in favour of the possibility of attaining demographic dividend for the country. In this connection, we should however keep in mind that, for integrating and utilizing the youth population in the growth process of the country requires increased investment in education and skill development program and to carefully plan and strategize in favour of it. Given that a significant percentage of youth work force of Bangladesh possesses 
no education with a very small percentage holds university degree, it is of paramount importance for upgrading the education level of the youth. In terms of technical and vocational training, similar scenario can be found, which requires similar policy focus too. A number of specific policy issues in this regard are as follows:

- There is no denying the fact that, the budgetary spending in education for Bangladesh is one of the lowest even among the developing countries. In order to utilize the proportional increase in youth population, it is crucial to provide quality education to them. With a view to achieve the 8 percent growth target as proposed in the $7^{\text {th }}$ Five Year Plan, the most important policy step would be to increase allocation in human resource development by a much greater margin.

- It is needless to mention that quality assessment is fundamental in education and skill development programmes. Monitoring of quality is important at all stages of educational programmes and effective implementation of relevant policies and projects should be given priority in this regard.

- Initiatives for youth development involves a number of ministries, e.g. Ministry of Education, Ministry of Primary and Mass Education, Ministry of Youth and Sports, Ministry of Women and Children Affairs, Ministry of Expatriates' Welfare and Overseas Employment etc. Effective coordination across the relevant personnel is critical in this regard for timely and efficient implementation of government programmes.

- With a view to link the policies of youth development to reduce poverty and to bring greater equity, specific demands for women as well as those in remote and lagging regions are needed to be considered.

Finally, it is needless to mention that, without effective monitoring and evaluation (M\&E) of government policies and relevant development expenditure, attaining desired result from existing initiatives can be difficult. Draft National Youth Policy 2016 along with the $7^{\text {th }}$ Five Year Plan has already emphasized about M\&E of relevant programmes. In this regard, conducting detailed yearly and mid term evaluation exercise and to take essential steps in terms of resource allocation should be done on a priority basis.

\section{References}

Ali, S., Alam, K. J., Islam, S., \& Hossain, M. (2015). An Empirical Analysis of Population Growth on Economic Development: The Case Study of Bangladesh. International Journal of Economics, Finance and Management Sciences, 3(3), 252-259. https://doi.org/10.11648/j.ijefm.20150303.21

Ali, S., Ali, A., \& Amin, A. (2013). The impact of population growth on economic development in Pakistan. Middle-East Journal of Scientific Research, 18(4), 483-491.

Ashford, L. (2007). Africa’s Youthful Population: Risk or Opportunity?, Population Reference 
Bureau, Washington, D.C.

Bangladesh Bureau of Statistics (2013). Labour Force Survey Report 2013. Dhaka: Bangladesh Bureau of Statistics, Ministry of Planning (GOB) Government of Bangladesh.

Bloom, D. E., Canning, D., Fink, G., \& Finlay, J. E. (2009). Fertility, female labor force participation, and the demographic dividend. Journal of Economic Growth, 14(2), 79-101. https://doi.org/10.1007/s10887-009-9039-9

Bloom, D., Canning, D., \& Sevilla, J. (2003). The demographic dividend: A new perspective on the economic consequences of population change. Rand Corporation.

Dickey, D. A., \& Fuller, W. A. (1979). Distribution of the estimators for autoregressive time series with a unit root. Journal of the American statistical association, 74(366a), 427-431. https://doi.org/10.1080/01621459.1979.10482531

Enders, W. (2008). Applied econometric time series. John Wiley \& Sons.

Iqbal, K., Yasmin, N., \& Yaseen, M. R. (2015). Impact of Demographic Transition on Economic Growth of Pakistan. Journal of Finance and Economics, 3(2), 44-50.

Johansen, S. (1988). Statistical analysis of cointegration vectors. Journal of economic dynamics and control, 12(2), 231-254. https://doi.org/10.1016/0165-1889(88)90041-3

Nakibullah, A. (1998). Population growth and development: the case of Bangladesh. Applied economics letters, 5(4), 231-234. https://doi.org/10.1080/135048598354870

Roudi, F. (2011). Youth Population and Employment in the Middle East and North Africa: Opportunity or Challenge?, United Nations Expert Group Meeting on Adolescents, Youth and Development, UN/POP?EGM-AYD/2011/06.

Thuku, G. K., Paul, G., \& Almadi, O. (2013). The Impact of Population Change on Economic Growth in Kenya. Management, 2(6), 43-60.

UNFPA (2014). "The Power of 1.8 Billion: Adolescents, Youth and the Transformation of the Future: UNFPA State of World Population 2014.” UNFPA, Washington D.C.

\section{Note}

Note 1. Demographic dividend can be defined as: “...... the accelerated economic growth that may result from a decline in a country's mortality and fertility and the subsequent change in the age structure of the population" (Population Reference Bureau, 2012). 


\section{Copyright Disclaimer}

Copyright for this article is retained by the author(s), with first publication rights granted to the journal.

This is an open-access article distributed under the terms and conditions of the Creative Commons Attribution license (http://creativecommons.org/licenses/by/3.0/). 